Pacific Journal of Mathematics

ASYMPTOTICALLY STABLE DYNAMICAL SYSTEMS AR 


\title{
ASYMPTOTICALLY STABLE DYNAMICAL SYSTEMS ARE LINEAR
}

\author{
ROGER C. MCCANN
}

\begin{abstract}
If $\pi$ is a dynamical system on a locally compact metric space $X$ which has a globally asymptotically stable critical point, then $\pi$ can be embedded into a dynamical system on $l_{2}$ which is derived from a linear differential equation. If $X$ is $n$-dimensional, then $l_{2}$ may be replaced by $R^{2 n}$.
\end{abstract}

Throughout this paper $R$ and $R^{+}$will denote the reals and nonnegative reals respectively. A dynamical system on a topological space $X$ is a continuous mapping: $\pi: X \times R \rightarrow X$ such that (where $\pi(x, t)=x \pi t)$

(i) $x \pi 0=x$ for all $x \in X$,

(ii) $(x \pi t) \pi s=x \pi(t+s)$ for all $x \in X$ and $s, t \in R$.

A point $p \in X$ is called a critical point of $\pi$ if $p \pi t=p$ for every $t \in R$. A subset $S$ of $X$ is called a section with respect to $\pi$ if $(S \pi t) \cap S=\phi$ for every $t \neq 0$. A subset $S$ of $X$ is said to be a section for $Y \subset X$ if $S$ is a section and $\{x \pi t: x \in S, t \in R\}=Y$. A compact subset $M$ of $X$ is said to be stable with respect to $\pi$ if for any neighborhood $U$ of $M$ there is a neighborhood $V$ of $M$ such that $\left\{x \pi t: x \in V, t \in R^{+}\right\} \subset U$. The compact subset $M$ of $X$ is said to be a global attractor if for any neighborhood $U$ of $M$ and $x \in X$, there is a $c \in R$ such that $x \pi t \in U$ whenever $c \leqq t$. If $M$ is a stable global attractor, then $M$ is said to be globally asymptotically stable.

Let $X$ and $Y$ be topological spaces on which are defined dynamical systems $\pi$ and $\rho$ respectively. We say that $\pi$ can be embedded into $\rho$ if there is a homeomorphism $h$ of $X$ onto a subset of $Y$ such that $h(x \pi t)=h(x) \rho t$ for every $x \in X$ and $t \in R$. In the special case $h(X)=Y$ we will say that $\pi$ is isomorphic to $\rho$.

The set of all sequences $x=\left\{x_{1}, x_{2}, \cdots, x_{n}, \cdots\right\}$ of real numbers such that $\sum_{n=1}^{\infty} x_{n}^{2}$ converges is denoted by $l_{2}$. If addition and scalar multiplication are defined coordinatewise and if a norm is defined by $\|x\|=\left(\sum_{n=1}^{\infty} x_{n}^{2}\right)^{1 / 2}$, then $l_{2}$ is a real Banach space.

Throughout the remainder of this paper $X$ will denote a locally compact metric space.

Let $p \in X$ be a globally asymptotically stable critical point with respect to the dynamical system $\pi$ and let $U$ be a compact neighborhood of $p$. It is known ([1, Theorem 2.7.14]) that there is a continuous (Liapunov) function $v: X \rightarrow R^{+}$such that

(i) $v(x)=0$ if and only if $x=p$,

(ii) $v(x \pi t)=e^{-t} v(x)$ for $x \in X-\{p\}$ and $t>0$. 
Let $a>0$ be so small that $v^{-1}(a) \subset U$ and set $S=v^{-1}(a)$. The following lemma is also well known and is easily verified.

LEMma 1. $S$ is a compact section for $X-\{p\}$. Moreover, the mapping $r: X-\{p\} \rightarrow R$ defined by $x \pi r(x) \in S$ is continuous.

Since $S$ is compact it is separable. Let $d$ denote a metric on $X$ and let $\left\{x_{n}\right\}$ be a countable dense subset of $S$. We define a countable number of continuous functions $f_{n}: S \rightarrow R^{+}$by

$$
f_{n}(x)=d\left(x, x_{n}\right) \text {. }
$$

LEMMA 2. If $f_{n}(x) \leqq f_{n}(y)$ for every $n$, then $x=y$.

Proof. Suppose that $x \neq y$. Let $r=d(x, y)$ and $B=\{z: d(z, y) \leqq$ $r / 4\}$. Since $\left\{x_{n}\right\}$ is dense in $S$ there is a $k$ such that $x_{k} \in B$. Then

$$
f_{k}(y)=d\left(y, x_{k}\right) \leqq \frac{1}{4} r<\frac{3}{4} d\left(x, x_{k}\right)=f_{k}(x) \text {. }
$$

A similar argument shows that there is a $j$ such that $f_{j}(x)<f_{j}(y)$. The desired result follows directly.

LEMMA 3. The mapping $h: S \rightarrow l_{2}$ defined by

$$
h(x)=\left(f_{1}(x), \frac{1}{2} f_{2}(x), \cdots, \frac{1}{n} f_{n}(x), \cdots\right)
$$

is a homeomorphism of $S$ onto $h(S)$.

Proof. Since $S$ is compact the mapping $d$ restricted to $S \times S$ is uniformly continuous and bounded. Hence, the set of mappings $\left\{f_{n}\right\}$ is equicontinuous and equibounded. For each $x \in S, h(x) \in l_{2}$ since $\left\{f_{n}\right\}$ is equibounded. Since $\left\{f_{n}\right\}$ is equicontinuous, $h$ is continuous. It follows immediately from Lemma 2 that $h$ is one-to-one. A continuous one-to-one mapping of a compact space onto a Hausdorff space is a homeomorphism.

Let $c \in(0,1)$ and define a dynamical system $\rho$ on $l_{2}$ by $x \rho t=c^{t} x$. This dynamical system can be interpreted as being derived from the linear differential equation $d y / d t=k y, y(0)=x$, where $k=\ln c$.

LEMMA 4. If $x, y \in S$ are such that $h(x)=h(y) \rho t$ for some $t \in R$, then $x=y$ and $t=0$.

Proof. Suppose that $h(x)=h(y) \rho t=c^{t} h(y)$ for some $t \in R$. Without loss of generality we may assume that $t \geqq 0$. Then $f_{n}(x)=c^{t} f_{n}(y) \leqq$ $f_{n}(y)$ for every $n$. By Lemma $2, x=y$. If $x=y$, clearly $t=0$. 
Lemma 5. The mapping $H: X \rightarrow l_{2}$ defined by

$$
H(x)=\left\{\begin{array}{cl}
0 & \text { if } x=p, \\
c^{-r(x)} h(x \pi r(x)) & \text { if } x \in X-\{p\}
\end{array}\right.
$$

where $r$ is the mapping defined in Lemma 1, is a homeomorphism of $X$ onto $h(X)$.

$$
\begin{aligned}
\text { Proof. If } H(x)=H(y), x \neq 0 & \neq y, \text { then } \\
e^{-r(y)} h(y \pi r(y)) & =c^{-r(x)} h(x \pi r(x))
\end{aligned}
$$

so that

$$
h(y \pi \Upsilon(y))=h(x \pi \Upsilon(x)) \rho(\Upsilon(x)-\Upsilon(y)) .
$$

By Lemma 4, $y \pi \Upsilon(y)=x \pi \Upsilon(x)$ and $\Upsilon(x)-r(y)=0$. Hence, $x=y$ and $H$ is one-to-one. Since $\pi, r$, and $h$ are cotinuous on $X-\{p\}, H$ is continuous on $X-\{p\}$. We will now show that $H$ is continuous at $p$. Let $\left\{z_{i}\right\}$ be a sequence in $X-\{p\}$ which converges to $p$. We will first show that $r\left(z_{i}\right) \rightarrow-\infty$. Since $z_{i} \pi r\left(x_{i}\right) \in S$ and $V(z)=a$ for each $z \in S$, we have

$$
0<a=V\left(z_{i} \pi r\left(z_{i}\right)\right)=e^{-\Upsilon\left(z_{i}\right)} v\left(z_{i}\right) .
$$

We must have $r\left(z_{i}\right) \rightarrow-\infty$ since $v\left(z_{i}\right) \rightarrow 0$. Now

$$
H\left(z_{i}\right)=c^{-r\left(z_{i}\right)} h\left(z_{i} \pi r\left(z_{i}\right)\right) \longrightarrow 0
$$

because $c \in(0,1), \quad r\left(z_{i}\right) \rightarrow-\infty$, and $h(S)$ is compact with $0 \notin h(S)$. This proves that $H$ is continuous at $p$ so that $H$ is continuous. Note that $H(x)=h(x \pi r(x)) \rho(-r(x))$. A short calculation shows that $H^{-1}(H(x))=h^{-1}[H(x) \rho r(x)] \pi(-r(x))$ whenever $x \neq p$. Since $h^{-1}, H, \rho$, $r$, and $\pi$ are continuous on their respective domains, $H^{-1}$ is continuous on $H(X)-\{0\}$. Let $\left\{x_{i}\right\}$ be any sequence such that $H\left(x_{i}\right) \rightarrow 0$. Since $H\left(x_{i}\right)=c^{-r\left(x_{i}\right)} h\left(x_{i} \pi \Upsilon\left(x_{i}\right)\right)$ and $h(S)$ is compact with $0 \notin h(S)$ we must have $r\left(x_{i}\right) \rightarrow-\infty$. Then

$$
0<a=v\left(z_{i} \pi r\left(z_{i}\right)\right)=e^{-r\left(x_{i}\right)} v\left(x_{i}\right)
$$

so that we must have $v\left(x_{i}\right) \rightarrow 0$. Thus, $x_{i} \rightarrow p$. This proves that $H^{-1}$ is continuous at $0 . H$ is a homeomorphism.

THEOREM 6. Let $\pi$ be a dynamical system on a locally compact metric space $X$ and let $\rho_{c}, 0<c<1$, be the dynamical system on $l_{2}$ defined by $x \rho_{c} t=c^{t} x$. If $\pi$ has a globally asymptotically stable critical point, then $\pi$ can be embedded into $\rho_{c}$.

Proof. In light of Lemma 5 it remains to show that $H(x \pi t)=$ 
$h(x) \rho t$. It is easy to show that $r(x \pi t)=r(x)-t$. Hence,

$$
\begin{aligned}
H(x \pi t) & =c^{-r(x)+t} h((x \pi t) \pi(r(x)-t)) \\
& =c^{t} c^{-r(x)} h(x \pi r(x)) \\
& =c^{t} h(x) \\
& =h(x) \rho t .
\end{aligned}
$$

If $X$ is of finite dimension $n$, then $l_{2}$ can be replaced by $R^{2 n}$ in Theorem 6. This may be proved as follows. Let $S$ be a compact section for $\pi$. It is known that if $A$ is compact and $B$ is one dimensional, then $\operatorname{dim}(A \times B)=\operatorname{dim} A+\operatorname{dim} B$. This is cited in [2, page 34] and [5, page 302], and referenced as [3] in [5]. Since $S \pi R$ is homeomorphic with $S \times R$, we have $\operatorname{dim} S+1=\operatorname{dim} S+\operatorname{dim} R=$ $\operatorname{dim}(S \times R)=\operatorname{dim}(S \pi R) \leqq n$. Hence $\operatorname{dim} S \leqq n-1$. It is known that a $k$-dimensional space can be embedded in $R^{2 k+1},[2$, page 60 ]. Hence, $S$ can be embedded into $R^{2 n-1}$. The one point compactification of $R^{2 n-1}$ is $S^{2 n-1}$, the unit sphere in $R^{2 n}$. Thus, there is an imbedding $g: S \rightarrow S^{2 n-1} \subset R^{2 n}$. Consider the dynamical system $\alpha_{c}$ defined by the linear differential equation

$$
\frac{d y}{d t}=k y, \quad y(0)=x
$$

where $y: R \rightarrow R^{2 n}$ and $k<0$. Then $x \alpha_{c} t=c^{t} x$ for $t \in R, x \in R^{2 n}$, and $c=e^{k}$. Define $G: X \rightarrow R^{2 n}$ by

$$
G(x)=\left\{\begin{array}{cl}
0 & \text { if } x=p, \\
c^{-r(x)} g(x \pi r(x)) & \text { if } x \in X-\{p\} .
\end{array}\right.
$$

The proof that $G$ is a homeomorphism is essentially the same as the proof of Lemma 5. With this result the proof of the following theorem is identical with that of Theorem 6 .

THEOREM 7. Let $\pi$ be a dynamical system on an $n$-dimensional locally compact space $X$ and $\alpha_{c}, 0<c<1$, be the dynamical system on $R^{2 n}$ defined by $x \alpha_{c} t=c^{t} x$. If $\pi$ has a globally asymptotically stable critical point, then $\pi$ can be embedded into $\alpha_{c}$.

If $S$ can be embedded into $S^{k-1}$, then obvious modifications of the proof of Theorem 7 show that $\pi$ can be embedded into the dynamical system on $R^{k}$ defined by $x \alpha_{c} t=c^{t} x, 0<c<1$. If $X$ has dimension $n$, what is the smallest integer $k$ such that $S$ can be embedded into $S^{k-1}$ ? The author does not know, but conjectures that if $X=R^{n}$ then $S$ can be embedded into $S^{n-1}$. If this conjecture were true then $S$ would be homeomorphic to $S^{n-1}$. The proof of this, or the construc- 
tion of a counterexample, appears to be difficult. However, in the case $n=2$, the conjecture is true.

THEOREM 8. Let $\pi$ be a dynamical system on $R^{2}$ which has a globally asymptotically stable point $p$. If $S$ is any section for $X-\{p\}$, then $S$ is homeomorphic to $S^{1}$.

Proof. Evidently $S$ is compact and connected. Let $x$ and $y$ be any two points of $S$. Since $p$ is asymptotically stable $L^{-}(x)=$ $L^{-}(y)=\phi$. It is easy to show that $D=\{p\} \cup\{x \pi R\} \cup\{y \pi R\}$ is a curve which separates the plane into exactly two components. Moreover, $S \cap D=\{x, y\}$. Hence, $S-\{x, y\}$ has exactly two components. A continuum whose connection is destroyed by the removal of two arbitrary points is a simple closed curve, [5, page 99].

COROLlary 9. Let $\pi$ be a dynamical system on $R^{2}$ and let $\alpha_{c}$, $0<c<1$, be the dynamical system on $R^{2}$ defined by $x \alpha_{c} t=c^{t} x$. If $\pi$ has a globally asymptotically stable critical point, then $\pi$ is isomorphic to $\alpha_{c}$.

\section{REFERENCES}

1. N. P. Bhatia and G. P. Szegö, Dynamical Systems: Stability Theory and Applications, Lecture Notes in Math., No. 35, Springer-Verlag, Berlin, 1967.

2. W. Hurewicz and H. Wallman, Dimension Theory, Princeton U. Press, Princeton, 1941.

3. W. Hurewicz, Über den sogenannten Produktsatz der Demensionstheorie, Math. Ann., 102 (1930), 305-312.

4. L. Janos, A linearization of semiflows in Hilbert space $l_{2}$, Topology Proc. (Baton Rogue, LA), 2 (1977), 219-232.

5. K. Kurqtowski, Topology, Vol. I, Academic Press, New York, 1966.

6. M. H. A. Newman, Elements of the Topology of Plane Sets of Points, Cambridge

U. Press, Cambridge (Eng.), 1964.

Received August 9, 1978 and in revised form September 21, 1978.

Mississippi State University

MississipPI State, MS 39762 



\title{
PACIFIC JOURNAL OF MATHEMATICS
}

\section{EDITORS}

\author{
DONALD BABBITT (Managing Editor) \\ University of California \\ Los Angeles, CA 90024 \\ HUGo ROSSI \\ University of Utah \\ Salt Lake City, UT 84112 \\ C. C. MOORE \\ University of California \\ Berkeley, CA 94720
}

J. DugundJI

Department of Mathematics

University of Southern California

Los Angeles, CA 90007

R. FinN and J. Milgram

Stanford University

Stanford, CA 94305

\section{ASSOCIATE EDITORS}
E. F. BECKENBACH
B. H. Neumann
F. WolF
K. YOSHIDA

\section{SUPPORTING INSTITUTIONS}

\author{
UNIVERSITY OF BRITISH COLUMBIA \\ CALIFORNIA INSTITUTE OF TECHNOLOGY \\ UNIVERSITY OF CALIFORNIA \\ MONTANA STATE UNIVERSITY \\ UNIVERSITY OF NEVADA, RENO \\ NEW MEXICO STATE UNIVERSITY \\ OREGON STATE UNIVERSITY \\ UNIVERSITY OF OREGON
}

UNIVERSITY OF SOUTHERN CALIFORNIA

STANFORD UNIVERSITY

UNIVERSITY OF HAWAII

UNIVERSITY OF TOKYO

UNIVERSITY OF UTAH

WASHINGTON STATE UNIVERSITY

UNIVERSITY OF WASHINGTON

The Supporting Institutions listed above contribute to the cost of publication of this Journal, but they are not owners or publishers and have no responsibility for its content or policies.

Mathematical papers intended for publication in the Pacific Journal of Mathematics should be in typed form or offset-reproduced, (not dittoed), double spaced with large margins. Please do not use built up fractions in the text of the manuscript. However, you may use them in the displayed equations. Underline Greek letters in red, German in green, and script in blue. The first paragraph or two must be capable of being used separately as a synopsis of the entire paper. Please propose a heading for the odd numbered pages of less than 35 characters. Manuscripts, in triplicate, may be sent to any one of the editors. Please classify according to the scheme of Math. Reviews, Index to Vol. 39. Supply name and address of author to whom proofs should be sent. All other communications should be addressed to the managing editor, or Elaine Barth, University of California, Los Angeles, California, 90024.

50 reprints to each author are provided free for each article, only if page charges have been substantially paid. Additional copies may be obtained at cost in multiples of 50 .

The Pacific Journal of Mathematics is issued monthly as of January 1966. Regular subscription rate: $\$ 72.00$ a year (6 Vols., 12 issues). Special rate: $\$ 36.00$ a year to individual members of supporting institutions.

Subscriptions, orders for numbers issued in the last three calendar years, and changes of address should be sent to Pacific Journal of Mathematics, P.O. Box 969, Carmel Valley, CA 93924, U.S.A. Older back numbers obtainable from Kraus Periodicals Co., Route 100, Millwood, NY 10546.

PUBLISHED BY PACIFIC JOURNAL OF MATHEMATICS, A NON-PROFIT CORPORATION

Printed at Kokusai Bunken Insatsusha (International Academic Printing Co., Ltd.). 8-8, 3-chome, Takadanobaba, Shinjuku-ku, Tokyo 160, Japan.

Copyright (C) 1979 by Pacific Journal of Mathematics Manufactured and first issued in Japan 


\section{Pacific Journal of Mathematics}

\section{Vol. 81, No. $2 \quad$ December, 1979}

Ersan Akyildiz, Vector fields and equivariant bundles ............... 283

Ehrhard Behrends, The centralizer of tensor products of Banach spaces ( $a$ function space representation) ......................... 291

Geoffrey R. Burton, Congruent sections of a convex body ............. 303

John Warnock Carlson, $H$-closed and countably compact extensions ...... 317

Robert Charles Carlson, Eigenfunction expansions for selfadjoint

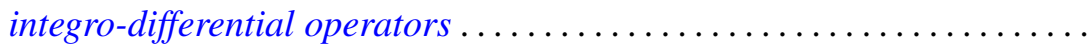

Robert Damiano, Coflat rings and modules.

Eric Karel van Douwen and Washek (Vaclav) Frantisek Pfeffer, Some properties of the Sorgenfrey line and related spaces ................

Uri Elias, Necessary conditions and sufficient conditions for disfocality and

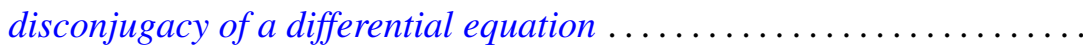

V. L. (Vagn Lundsgaard) Hansen, Polynomial covering spaces and homomorphisms into the braid groups .......................

Paul Hess, Dedekind's problem: monotone Boolean functions on the lattice

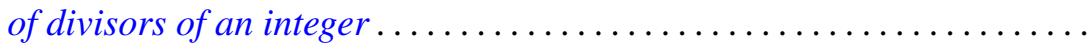

Alan Hopenwasser and David Royal Larson, The carrier space of a reflexive

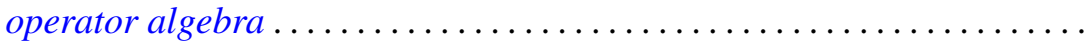

Kyung Bai Lee, Spaces in which compacta are uniformly regular $G_{\delta} \ldots \ldots$.

Claude Levesque, A class of fundamental units and some classes of

Jacobi-Perron algorithms in pure cubic fields...

Teck Cheong Lim, A constructive proof of the infinite version of the

Belluce-Kirk theorem ..........................

Dorothy Maharam and A. H. Stone, Borel boxes

Roger McCann, Asymptotically stable dynamical systems are linear

Peter A. McCoy, Approximation and harmonic continuation of axially symmetric potentials in $E^{3} \ldots \ldots \ldots \ldots \ldots \ldots \ldots$

Takahiko Nakazi, Extended weak-* Dirichlet algebras ....

Carl L. Prather, On the zeros of derivatives of balanced trigonometric polynomials ................................

Iain Raeburn, An implicit function theorem in Banach spaces...

Louis Jackson Ratliff, Jr., Two theorems on the prime divisors of zeros in completions of local domains...

Gloria Jean Tashjian, Cartesian-closed coreflective subcategories of

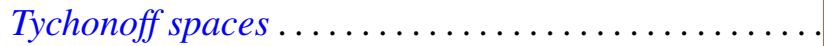

Stephen Edwin Wilson, Operators over regular maps.... . . 